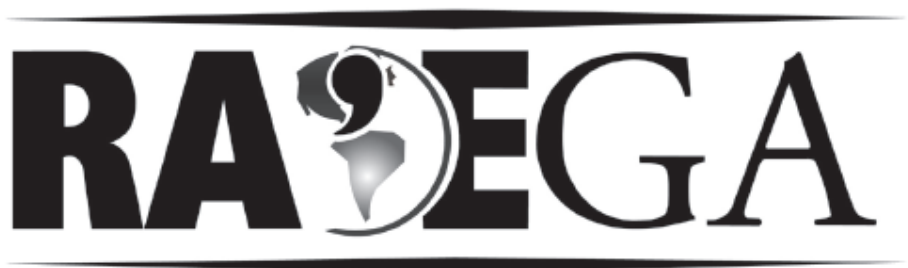

O ESPAÇO GEOGRÁFICO EM ANÁLISE

\title{
TERRITÓRIO E CRIAÇÃO DE MUNICÍPIOS: O SIGNIFICADO TEỎRICO-POLÍTICO DA COMPARTIMENTAÇÃO DO ESPAÇO
}

\section{TERRITORY AND MUNICIPAL CREATION: THE THEORETICAL POLITICAL SIGNIFICANCE OF SPACE COMPARTMENTATION.}

\author{
Adilar Antonio Cigolini ${ }^{1}$
}

\begin{abstract}
RESUMO
O presente artigo traz uma reflexão acerca de um tema que adquiriu grande visibilidade na história da divisão política do Brasil contemporâneo: a criação de municípios. Na década de 90 do século XX, sobretudo, o Brasil viu aumentar significativamente o número de recortes territoriais do governo local, fato que levou muitos pesquisadores estudar a temática, especialmente suas causas e conseqüências. O presente texto procura pensar o significado do processo de forma teórica, embasado fortemente na obra de Jean Gottmann, autor que buscou elucidar o significado da divisão do território em unidades políticas. $O$ artigo apresenta também as características do governo local em vários países do mundo, como forma de mostrar que a existência do governo local, independente do seu papel na estrutura governamental de cada país, está vinculada à busca de autonomia e oportunidade.
\end{abstract}

Palavras-chave: criação de municípios; divisão do território; governo local; Jean Gottman

\footnotetext{
1 Geógrafo, Professor do Departamento de Geografia da Universidade Federal do Paraná, Curitiba, Paraná, Brasil. adilar@ufpr.br
} 


\section{ABSTRACT}

The following article brings us a reflection regarding a subject of great significance on contemporaneous history of the internal political boundaries in Brazil. During the last decade of the twentieth century, Brazil has seen a significant increase on the amount of territorial parting of local governance. Such matter has led many researchers to study this theme, specially its causes and consequences. This article, however, tries to reason on the significance of this process through theoretical means, firmly grounded on the works of Jean Gottmann, author that has tried to elucidate the meaning of territorial division on political unities. The article also demonstrate local government characteristics on many countries around the world, in order to show that the existence of local government, regardless of its role on governmental structure in each if these countries, is bound to the pursuit of autonomy and opportunity.

Key-words: municipal creation; territorial parting, local government, Jean Gottmann.

\section{INTRODUÇÃO}

A comparação entre a divisão político-administrativa brasileira representada num mapa do ano de 1980 e aquela representada num mapa de 2010 mostra que, em 30 anos, o território sofreu um intenso processo de compartimentação. Aliás, somente em períodos muito curtos e em fases bem limitadas da história nacional é que se conseguiria observar, em mapas com essa temática, a mesma divisão do território. Novos recortes sempre foram gerados, tanto no que diz respeito às divisões regionais, mas, sobretudo, na compartimentação do espaço em municípios. Esse fenômeno chamou a atenção da imprensa e da sociedade, como um fato novo e, de modo geral, prejudicial.

Com vistas a refletir sobre a temática, o presente artigo traz uma discussão teórica acerca do significado político da compartimentação do espaço. A idéia é questionar um certo senso comum que, de modo geral, associa a criação de novas unidades políticas ao desperdício de recursos e formação de elites políticas. Tais discursos estão associados a uma visão econômica, sobretudo conservadora, ou sociológica, contribuindo pouco para o avanço de um debate pautado no conceito de território como unidade políticajurídica. 
O artigo é estruturado em 04 partes, sendo a primeira, a presente introdução. Em seguida é feita uma discussão acerca da relação entre território e divisão política, com objetivo de esclarecer o sentido da divisão territorial, permitindo entender, para além de questões circunstanciais, porque se recorta o espaço. A referência básica dessa discussão é a obra de Jean Gottmann The significance of territory (1973). Outros autores, a exemplo de Claude Raffestin, Milton Santos, Iná Elias de Castro e Marcelo Lopes de Souza, são, igualmente, trazidos a essa discussão como forma de traçar um diálogo com Jean Gottman, enriquecendo a reflexão sobre a compartimentação do território. A terceira parte apresenta algumas realidades distintas no que diz respeito a compartimentação territorial do governo local no mundo. A idéia é mostrar que existem diferentes experiências na forma de conceber o governo local, bem como há uma variação muito grande no número dessas unidades em cada país. Entretanto, mesmo em realidades diferentes há um sentido comum na existência de tais territórios: a busca de autonomia e oportunidade, denotando o caráter universal do sentido de território.

Por fim, nas considerações finais, apresenta-se uma reflexão que procura evidenciar o significado da divisão do território, permitindo entender o sentido político da criação de municípios no Brasil.

\section{O SIGNIFICADO DA DIVISÃO POLÍTICA: O TERRITÓRIO COMO AUTONOMIA E OPORTUNIDADE}

Santos (1996) diz que o Estado Nacional foi um marco, um divisor de águas na construção de uma noção jurídico-política do território que, ao mesmo tempo, fundamentava e moldava o próprio Estado. Essa noção, entretanto, na atualidade, incorpora novos vetores, e seu uso faz dela objeto de análise social, tornando antiga a noção de Estado Territorial. Por isso, o autor usa uma metáfora: o retorno do território. Ele esclarece: o retorno se dá porque, mesmo que o território clássico, do estado nacional, tenha sido questionado, o conceito renovado incorpora novamente um papel ativo. 
De fato, os trabalhos de Haesbaert (1997; 2004) e Saquet (2007) mostram a amplitude que o território adquiriu, sendo atualmente utilizado em muitas tendências científicas. Em Santos e Becker (2006) encontram-se estudos que mostram o viés objetivo e pragmático do conceito, que permite leituras multiescalares e o uso operacional para ação estatal, privada ou de grupos sociais diversos. Entretanto, embora permita uma multiplicidade de abordagens, o conceito incorpora sempre a relação entre sociedade e espaço. Essa concepção não seria nova. Ao resgatar a trajetória da sua evolução, Gottmann (1973) mostra que a noção de território foi sempre usada para designar certa extensão do espaço delimitado por linhas concordadas entre autoridades políticas vizinhas. E, mesmo que essas linhas tenham sido frequentemente questionadas, modificadas e redefinidas, politicamente 0 território sempre foi uma área dentro de limites mutuamente reconhecidos. Em consequência, o conceito historicamente designou a relação entre grupos politicamente organizados e o espaço, e expressaria a busca de soluções fundamentais na existência dos grupos, já que o espaço, quando convertido em território, servia como a casa, um abrigo contra a agressão por estranhos e como área onde se encontravam os recursos para a sobrevivência.

Decorreu disso a associação entre espaço e organização política, pois a delimitação não somente trazia consigo a questão da jurisdição interna por uma estrutura política, o que exigia uma organização com um elemento de centralidade, como também colocava a questão do estabelecimento das relações com os outros grupos. Dessa forma, o território desempenhou, por um lado, a função de segurança e, por outro, serviu como trampolim para oportunidade. Tais funções, ao exigir a organização das relações internas e externas do território, geram um elemento de conflito: a busca da segurança pode ser antagônica ao anseio por maiores oportunidades. A primeira revelaria a busca de um isolamento relativo e a segunda, um grau de interdependência com o exterior.

Para Gottmann (1973), isso se constata desde a origem do conceito, pois, embora muitos povos ditos civilizados pareçam aspirar à universalidade, desde o início da história dividiam o espaço, criando unidades políticas para 
ajustar-se a outros grupos. Em princípio, isso parece uma prática contraditória, mas seria justamente o que teria dado significação ao território nos diversos períodos de sua evolução. Raffestin (1993, p. 150) concorda que "[...] nenhuma sociedade, por mais elementar que seja, escapa à necessidade de organizar o campo operatório de sua ação", enquanto Santos (2000, p. 80) diz que, "Ao longo da história humana, olhando o planeta com um todo ou observando através dos continentes e países, o espaço geográfico sempre foi objeto de uma compartimentação".

Para Gottmann (1973), essa evolução foi lenta e permanente, passando por várias fases. A formação da densidade teria sido a primeira dessas fases, quando o homem se juntou em cidades ou em agrupamentos, formando comunidades. Os agrupamentos, ao estabelecer uma vida comunal, exigiram, em primeiro lugar, a existência de regras que permitissem a vida comunitária e, em consequência, de uma autoridade que fizesse cumprir essas leis.

Um segundo momento, que teria sido decisivo na evolução do conceito, foi no período de Alexandre, o Grande (356-323 a.C.), que tinha um projeto universal, mas dividiu todo seu império em províncias. Essas frações geraram uma noção de partições com centralidade, que foi posteriormente assimilada pelo Império Romano e permaneceu mesmo depois de sua queda. Uma outra fase teria sido iniciada por volta do século $X V$, quando do delineamento dos territórios de reinos como a França, Inglaterra e Espanha, cujos habitantes possuíam certa identidade nacional. Foi um período de progressão e consolidação de atividades mercantilistas. $O$ mundo, com a descoberta de novos continentes, expandiu-se, mas, ao expandir-se, compartimentou-se segundo os interesses das potências.

Gradualmente, entre os séculos XVI e XVIII, a submissão pessoal, base da proteção medieval, foi substituída pela submissão ao estado soberano, cujo elemento central da soberania passou a ser o território. Desde então, uma das principais preocupações do processo político teria sido a divisão do espaço geográfico, relacionado à ideia de nacionalismo, estando, portanto, relacionado a comunidades nacionais, que requereram "[...] um compartimento territorial, 
dentro do qual a comunidade assumiu a responsabilidade pelo próprio destino e viveu de acordo com seu próprio sistema de leis." (GOTTMANN, 1973, p. 99100).

O exercício da soberania territorial como conceito do estado nacional espalhou-se pelos continentes e estabeleceu um modelo de organização política. Segundo o autor, nas primeiras décadas do século XX, já estava bastante claro que os impérios ainda existentes seriam desmantelados e compartimentados em unidades nacionais. Em meados daquele século, já havia um grande e variado número de estados soberanos independentes, que cobriam a maior parte do planeta. A crescente divisão territorial foi a tendência do século $X X$ e, mesmo com a emergência de agrupamentos regionais entre Estados, respeitou-se a soberania dos países participantes.

Mas, para Gottmann (1973), esse movimento parece ter alcançado seu apogeu, pois a blindagem alcançada na lenta evolução dos estados soberanos baseados na exclusiva jurisdição territorial tem sido questionada. Na visão do autor, iniciou-se outro momento decisivo no processo de ressignificação do território. Essa ressignificação está relacionada com o que denominou de falecimento da função de abrigo que o território proporcionava, pois as novas relações entre os estados questionaram o tipo de segurança e privacidade que a soberania territorial assegurava.

A fronteira é uma partição - um instrumento de blindagem na
organização do espaço acessível. Ela esconde e até certo ponto
controla o movimento de fora do território. [...] ela perdeu muito de
seu potencial de blindagem militar com o advento da tecnologia
moderna [...] muito do seu poder para controlar a migração e o
movimento de bens, com a liberalização do comércio e do
desenvolvimento do trabalho desde meados do século XX e, embora
[...] situações de escassez e desigualdade podem causar algum
retorno a atitudes mais paroquiais ou mais nacionalistas, acredita-se
que uma completa reversão de tendências internacionalistas é,
entretanto, improvável. (GOTTMANN, 1973, p. 138-139).

Nessas circunstâncias, diz, a eficiência da soberania como garantia de segurança é restrita, mas ainda é uma condição necessária, embora não suficiente, para organizar segurança e oportunidade. Dessa forma, a ressignificação do conceito relativiza a questão da segurança, que atualmente é inatingível, mas o território continuaria sendo base para qualquer exercício de 
soberania. Essa, embora tenha perdido parte de suas características, tem adquirido, em termos de organização internacional, o valor de um cartão de união em todos os arranjos coletivos entre estados, na escala regional ou global, ou seja, possui uma função social internacional.

O território proporciona a uma comunidade separações definidas, pelo menos em termos de lei e governo próprio; mas isto também proporciona à comunidade uma capacidade de complementaridade com o exterior, e no final das contas com o mundo. Esta complementaridade reside, primeiramente, nos recursos materiais do território que inclui o local como também a habilidade dos habitantes [...] e secundariamente, confia o privilégio de estados soberanos participarem em debates de porte internacional. Território é a base para alguma igualdade entre estados, não importando a variação no tamanho deles. (GOTTMANN, 1973, p. 156).

Além disso, o território tem ainda um papel na organização interna política dos grupos, pois

[...] estabelece uma estrutura que serve aos interesses da comunidade que o habita. Qualquer organização de uma comunidade política terá que lidar com as estruturas internas de um pouco de variedade, um pouco de oposições e conflitos, requerendo tolerância mútua e um desejo de coexistência. (GOTTMANN, 1973, p. 148).

Gottmann (1973, p. 147) esclarece que essa jurisdição "[...] determina uma grande quantidade de direitos do indivíduo: designa se é ou não um cidadão de certo país, estado, ou cidade". Diz o autor, que a divisão determina ainda se os indivíduos pertencem a uma dada comunidade e se o fazem, sobre quais condições regulamentos. Por incorporar a existência da vida comunitária, práticas políticas, relações hierárquicas e o exercício da autoridade, que exigem a regulação do espaço em função das opções políticas dos grupos, o território continua se adaptando às realidades emergentes, sendo ainda "[...] uma questão central da história humana e de cada país [...]." (SANTOS; SILVEIRA, 2001, p. 20).

Tanto do ponto de vista interno como externo, o território expressa a possibilidade da organização política, o que permite certo nível de autonomia ao grupo e a inserção no sistema de relações interestatais, que reconhece a comunidade política pelo reconhecimento da jurisdição dessa comunidade sobre uma porção do espaço. Essa concepção de território - como espaço 
político formal - vincula-se à tradição histórica da geografia política, cujo marco inicial pode ser atribuído a Ratzel. Entretanto, ao contrário desse autor, a construção conceitual de Gottmann, embora tenha tido como referência a escala do Estado-nação, território que se funda sob o conceito de soberania, não vincula o espaço político a uma única escala ou ator, o Estado.

Cox (1998) confirma a redefinição do conceito, pois atualmente, além de designar espaços de jurisdições formais nas mais variadas escalas, emerge como possibilidade explicativa para conflitos em qualquer relação social localizada, mas permanece como "[...] um conceito central na geografia política, talvez o único conceito definidor, sem o qual esse campo não existiria". (COX, 1998, p. 6-7). Na mesma direção Souza (2003) argumenta que o território pode ser entendido em escala nacional e em associação com o Estado, mas que expressa, igualmente, uma riqueza de situações.

Territórios existem e são construídos (e desconstruídos) nas mais diversas escalas, da mais acanhada (p. ex., uma rua) à internacional (p. exemplo a área formada pelo conjunto dos territórios dos paísesmembros da Organização do Tratado do Atlântico Norte - OTAN); territórios são construídos (e desconstruídos) dentro de escalas temporais as mais diferentes: séculos, décadas, anos, meses ou dias; territórios podem ter um caráter permanente, mas também podem ter uma existência periódica, cíclica. (2003, p. 81).

Raffestin vê significado semelhante quando diz que o território é o resultado da ação de um ator sintagmático em qualquer nível "[...] do Estado ao indivíduo, passando por todas as organizações pequenas ou grandes, encontram-se atores sintagmáticos que 'produzem' o território." (1993, p. 152). Para Souza (2003), antes de espaço concreto, o território é formado pelas relações sociais projetadas sobre o espaço. Desse modo, o conceito é definido pelas relações, que muitas vezes são

[...] orientadas à conquista da autonomia das sociedades locais. A autonomia não significa auto-suficiência, não implica o fechamento com relação ao exterior, mas a capacidade de autogoverno das relações de territorialidade, internas e externas, de autoprojeção de um desenvolvimento centrado nessas relações. (DEMATTEIS apud SAQUET, 2007, p. 9).

Gottmann (1973) constrói sua argumentação refletindo sobre um 
território baseado no princípio da soberania. Entretanto, a reflexão do seu trabalho à luz do desenvolvimento do conceito permite incorporar outras escalas à análise, incluindo aquela dos municípios, considerados como territórios formais que recortam o espaço. (MOURA e ULTRAMARI, 1993). Para Castro o município é uma escala e um território político por excelência, sendo que "[...] é no conhecimento da dinâmica da ocupação do território, da organização das sociedades locais e dos seus interesses que as decisões políticas e os modos de organização do território do país, como resultados concretos dessas decisões, adquirem significado". (2005, p.134).

Santos (2002), ao refletir sobre da criação de estados e municípios, argumenta que, na atualidade, o exercício da cidadania e as condições para a acessibilidade política dependem da forma como se organizam as divisões territoriais. A sociedade se constitui através de um pacto social, cuja existência está intrinsecamente ligada a um pacto territorial, mesmo que isso muitas vezes não esteja explicitado. Os objetivos e conteúdos de ambos são mutáveis, exigindo diferentes arranjos e configurações à medida que a sociedade apresenta novas necessidades e, desse modo, não se pode conceber o espaço com recortes geográfico-políticos imutáveis. "Por isso, as divisões e subdivisões territoriais, através da conformação dos Estados, municípios e outras configurações, não são apenas uma moldura, um dado passivo, mas constituem um elemento ativo do quadro de vida". (SANTOS, 2002, p.34). A divisão do território, desse modo, não se funda em aspectos funcionais determinados por ações e interesses específicos, mas adquire um significado estrutural e, inscreve-se nas formas e no conteúdo da vida social, em qualquer escala geográfica.

\section{A DIVERSIDADE DOS GOVERNOS LOCAIS: ALGUNS EXEMPLOS INTERNACIONAIS}

Se, por um lado, a divisão do mundo em Estados-nações proporciona às comunidades políticas segurança e oportunidade, pela inserção no sistema estatal internacional pelo princípio da soberania, permitindo a organização das 
relações externas dessa comunidade, do ponto de vista interno, a organização do território requer a existência de governos locais.

Autores como Noronha (1997), Lima (2000), Tomio (2002), Blasi (1982), Olowu (1982) e Corralo (2006) mostraram a diversidade de governos locais existentes no mundo e fizeram comparações entre o número de municípios em diversos países. Tais leituras auxiliam na reflexão sobre o governo local brasileiro. A Tabela 1 traz a relação entre extensão territorial, população e o número de governos locais em alguns países.

TABELA 1 - PAÍSES SELECIONADOS: NÚMERO, HABITANTES E EXTENSÃO TERRITORIAL DOS GOVERNOS LOCAIS.

\begin{tabular}{l|c|c|c|c|c}
\hline \multicolumn{1}{c|}{ PAÍs } & $\begin{array}{c}\text { No. DE } \\
\text { GOVERNOS } \\
\text { LOCAIS }\end{array}$ & $\begin{array}{c}\text { NÚMERO DE } \\
\text { HABITANTES }\end{array}$ & $\begin{array}{c}\text { ÁREA DO } \\
\text { PAÍS - km2 }\end{array}$ & $\begin{array}{c}\text { HABITANTES } \\
\text { POR } \\
\text { GOVERNO } \\
\text { LOCAL }\end{array}$ & $\begin{array}{c}\text { ÁRA } \\
\text { MÉDIA } \\
\text { POR } \\
\text { GOVERNO } \\
\text { LOCAL - } \\
\text { km2 }\end{array}$ \\
\hline França & 36.000 & 62.150 .775 & 545.630 & 1.726 & 15 \\
\hline Alemanha & 8.400 & 82.369 .552 & 357.021 & 9.805 & 42 \\
\hline Espanha & 8.049 & 40.491 .052 & 504.782 & 4.993 & 63 \\
\hline Grécia & 6.036 & 10.722 .816 & 131.940 & 1.776 & 22 \\
\hline Itália & 8.000 & 58.145 .300 & 301.230 & 7.268 & 38 \\
\hline Brasil & 5.563 & 169.872 .855 & 8.511 .965 & 30.547 & 1.530 \\
\hline Áustria & 2.300 & 8.205 .533 & 83.870 & 3.567 & 36 \\
\hline Argentina & 2.157 & 40.482 .000 & 2.766 .890 & 18.767 & 1.282 \\
\hline Holanda & 800 & 16.645 .313 & 41.526 & 20.806 & 52 \\
\hline Austrália & 700 & 21.007 .310 & 7.686 .850 & 30.010 & 10.981 \\
\hline Reino Unido & 484 & 60.943 .912 & 244.820 & 125.917 & 505 \\
\hline Dinamarca & 276 & 5.484 .723 & 43.094 & 19.873 & 156 \\
\hline Portugal & 275 & 10.676 .910 & 92.391 & 38.825 & 335 \\
\hline FONTE: & & & & & \\
\hline
\end{tabular}

FONTE: organizado por A. Cigolini (2009), com base no número de governos locais constantes em Batley e Stoker (1991) e Corralo (2006).

NOTA: O número de habitantes e a extensão territorial foi atualizado de acordo com as informações do site https://www.cia.gov/library/publications/the-world-factbook/geos/, acessado em 26.01.2009. 
Em primeiro lugar, comparando-se as informações, constata-se a diversidade de situações. Num extremo, a França tem 36.000 unidades políticas locais, e a extensão territorial e o número de habitantes de cada unidade é reduzido. Já em países como o Reino Unido e Portugal, os governos locais têm considerável extensão territorial e significativo número de habitantes por unidade.

Quando comparou o Brasil com os outros países, Noronha (1996) concluiu que ele é pouco compartimentado. Tomio diz que esse tipo de comparação "[...] é um argumento absurdo, visto que a organização políticoadministrativa e o grau de autonomia desses países são muito distintos da brasileira." (2001, p. 35). Caldas (2002) também questiona a comparação entre diferentes países, pois cada qual tem um sistema de governos locais com características próprias, o que tornaria inviável a comparação.

Mas o uso da comparação é recomendável justamente para perceber as diferenças e semelhanças dos fenômenos, não tendo nenhum sentido comparar o que é igual. A percepção das diferenças e semelhanças, por sua vez, permite raciocínios e correlações entre as diversas situações. Admite-se, entretanto, que, no caso em questão, a comparação se tornaria mais eficaz se, ao invés de se utilizar, como fez Noronha (1996), o termo município, que designa uma situação particular, fosse utilizado o termo governo local, que exprime, de modo geral, a diversidade das comunidades políticas locais. Desse modo, comparando-se o número de governos locais existentes nos países especificados na Tabela 1 e, mesmo reconhecendo-se a existência de diferentes modelos, que pressupõem a organização diferenciada de governos locais, nota-se que no Brasil a área média do governo local é maior que as demais, à exceção da Austrália, que tem maior população e área por governo local. Países como o Reino Unido e Portugal, entretanto, mesmo tendo menor área média, têm maior população média por município do que o Brasil.

O número de governos locais, bem como sua forma de organização, resulta de diferentes concepções políticas, oriundas dos diversos referenciais e experiências históricas cada país. A Alemanha, segundo Krell (2003, p. 43), 
km2. O país possui 16 Estados federados e cerca de 14.500 municípios: aproximadamente 8.500 na parte ocidental (65 milhões de habitantes) e 6.000 no território da antiga República Democrática (15 milhões de habitantes).

Naquele país, há uma variedade de governos locais e, igualmente, uma variedade de funções, segundo os estados federados. Em alguns, o prefeito (gestor) é eleito, enquanto em outros é escolhido pelo Conselho local. Os governos locais aplicam leis federais, estaduais e os regulamentos próprios, sendo responsáveis por executar aproximadamente $80 \%$ de todas as leis federais e estaduais, o que Ihes confere um duplo caráter, tendo ao mesmo tempo a autoadministração e a responsabilidade como órgão executor de seu respectivo estado federado e da União. No Brasil, pelo contrário, os governos locais não são obrigados a executar leis de outras escalas.

Os estatutos dos governos locais alemães não são leis oriundas de autonomia, mas normas administrativas. Tais estatutos são bastante influenciados segundo o estado federado em que se encontram. A autoadministração local não separa os poderes legislativos e executivos. Atualmente, segundo Krell, os governos locais têm perdido sua espontaneidade e o controle torna-se cada vez maior.

\begin{abstract}
$\mathrm{Na}$ verdade, o volume das funções delegadas exercidas pelo município alemão torna-se cada vez maior, convertendo o município, cada vez mais, em instância local do Estado. Por outro lado, os municípios preferem executar tarefas estaduais com seus próprios servidores a admitir a instituição de uma série de órgãos estaduais específicos em seu território, o que, certamente, iria destruir a unidade da administração pública. (2003, p. 66).
\end{abstract}

Outro caso, além dos expostos na tabela, é o dos Estados Unidos, onde também existem formas diferentes de organização das comunidades políticas locais. Katz informa que há mais de 36.000 grandes e pequenas cidades naquele país. Apesar disso, "[...] 123 milhões de americanos - quase 50 por cento do total da população - vivem em cidades de menos de 10.000 habitantes, em comunidades que podem, ou não, ser constituídas como municípios ou em áreas rurais." (KATZ, 2004, p. 46).

Naquele país, todos os estados, com exceção de Connecticut e Rhode Island, são divididos em condados, subdivisões que cobrem extensos 
territórios, regidos por legislação estadual. Os serviços de cada condado variam em função das suas características, pois ele pode ser rural, urbano, suburbano, ou mesmo apresentar essas três situações. Os distritos são outra divisão territorial, parte dos condados. Prestam serviços governamentais, como a coleta de lixo, mas não possuem documento próprio.

As cidades são consideradas como município, ou seja, possuem um documento constitutivo legal outorgado pelos estados. Os serviços prestados pelos governos das cidades dependem das características locais e são especificados no seu documento constitutivo. O número de habitantes pode definir os tipos de serviços que cada local pode executar. Muitas comunidades, pelo reduzido número de habitantes, unem-se a comunidades vizinhas ou firmam contratos com o governo do estado ou do condado para a prestação de serviços. Dessa forma,

[...] os governos locais não são inteiramente autônomos $e$ independentes. Eles fazem parte da estrutura geral da Constituição e das leis de um estado, da mesma forma que os próprios estados americanos fazem parte da estrutura da Constituição dos Estados Unidos. Na verdade, alguns estados - Connecticut, New Hampshire, e muitos estados da Nova Inglaterra e da faixa intermediária da costa do Atlântico, por exemplo - operam quase como se fossem federações das suas comunidades locais. No entanto, outros estados - Idaho, Novo México e muitos estados do Oeste e do Sul - são consideravelmente mais centralizados e controlam cuidadosamente as operações das suas comunidades locais. (KATZ, 2004, p. 53).

Para ilustrar a diversidade de governos locais nos Estados Unidos, Rodrigues (1995, p. 43) cita o exemplo: "Como consequência da evolução histórica, são diversos os governos locais do Estado de Nova lorque, os quais se sobrepõem tanto em termos de atribuição como de jurisdição". Segundo ele, somente naquele estado existe um total de 9.203 governos locais, com média de 1.196 habitantes para cada governo.

Corralo (2006) informa que na Argentina há uma variação na autonomia e formas organizativas de acordo com cada uma das províncias. $\mathrm{Na}$ Austrália, não há menção ao governo local, nem às suas respectivas autonomias na Constituição do país. Tais questões ficam a cargo dos estados, havendo igualmente diferenças de autonomia e formas organizativas segundo cada um deles. Na Áustria, a autonomia e competências dos governos locais 
são expressas na Constituição Federal, mas a forma de autonomia é variável segundo o número de habitantes. Países como México, Índia e Rússia internamente apresentam diversas formas de conceber o governo local, possuindo autonomia política, financeira e administrativa, em diferentes graus.

A diversidade com que o governo local aparece no mundo mostra que a existência de grupos pressupõe, mesmo em tempos e lugares distintos, uma comunidade política organizada territorialmente. De acordo com Azevedo (apud CORRALO, 2004, p. 14),

O município, como já se disse, é a associação natural de vizinhos, grupo intermediário entre o indivíduo e o Estado, com funções de realizar os serviços comuns. Não se pode dizer, portanto, que ele seja criado pelo Estado-membro, cujo vocábulo traduz o sentido de geral, tirar do nada, dar existência. Ora, não é isso o que realmente ocorre. O Estado-membro não cria o Município, ele apenas o reconhece. [...] Poder-se-ia dizer que o Estado cria o Município do ponto de vista jurídico-formal; isto é, cria o Município como entidade jurídica [...].

Corralo (2006), revisando a contribuição de diversos autores que tratam dessa temática, mostra que há quatro formas de compreender o fenômeno municipal:

a) como fenômeno histórico ou germânico, que considera o município uma criação espontânea, logo assimétrica, em vista das diversas variáveis, não constituindo mera criação legal;

b) pelo sistema legal francês, em vista da tendência centralizadora, que considera os municípios como entidades administrativas;

c) pela concepção jusnaturalista, que considera o município como uma associação natural de todos os povos;

d) como fenômeno econômico, compreendendo-o em função da satisfação das necessidades locais.

De maneira geral, esse autor resume o entendimento sobre a natureza do município de três formas: histórica, em que o município é anterior ao Estado; sociológica, em que o município é uma comunidade, sociedade local e territorial, com laços de solidariedade, e filosófica, em que o município é considerado uma entidade natural, que busca o bem comum. Defende, entretanto, que o município se constitui dentro de uma espacialidade estatal, 
pois, mesmo sendo constituído por território, povo e poder e embora possua uma conformação natural, "[...] depende de uma espacialidade estatal que o abranja e delimite os seus limites, que, por sua vez, devem resguardar o mínimo de autonomia para que os interesses locais possam ser satisfeitos." (CORRALO, 2006, p. 105).

Para Rech (2000, p. 117), "A submissão de uma determinada sociedade ou comunidade a uma ordem internacional ou nacional, sem autonomia necessária aos limites de suas próprias necessidades e diversidades, resulta na restrição de direitos fundamentais, diante das imposições impostas". Dessa forma, a existência da comunidade requer um território, enquanto fator de autonomia, e se inscreve no conjunto daqueles direitos a que se deve ter acesso pelo próprio fato da sua existência. Rech mostra que, desde a origem, os municípios foram unidades de organização política.

\begin{abstract}
As comunidades, representadas pelos municípios, com identidades distintas, têm necessidade de preservar direitos locais de seus munícipes, mas não têm poder de regulamentação para a sua garantia. A diversidade de valores, da forma de viver, de se relacionar e de obter qualidade de vida, entre outras, são questões locais, constituindo-se interesses ou direitos diferenciados, que devem ser priorizados na sua garantia, mas que não podem ser impostos de cima para baixo, de forma universal, como comportamento único, descaracterizando-se de desrespeitando as próprias diferenças do ser humano e do espaço onde ele vive. (2000, p. 120).
\end{abstract}

Por isso Rech (2000) inscreve a autonomia municipal no quadro dos direitos fundamentais, inerentes aos princípios democráticos e à dignidade da pessoa humana, essencial ao desenvolvimento humano, cuja espacialidade, aberta à participação, permite o aprendizado num processo ininterrupto, que tem início, mas não fim.

O Brasil, em 2011, possui 5.563 governos locais, sendo todos considerados municípios. Krell (2003) afirma que, assim como a União e os estados, na sua área de jurisdição territorial, o município é detentor legítimo de poder estatal, tendo autonomia de natureza política e administrativa, fato que estabelece uma particularidade em relação aos governos locais. 
Sob o aspecto formal, o município brasileiro certamente é a entidade territorial local investida da autonomia mais abrangente no mundo inteiro. No exercício de suas atribuições, ele atua em absoluta igualdade de condições com as outras esferas governamentais; os atos municipais independem de prévia autorização ou de posterior ratificação de qualquer outra entidade estatal. (KRELL, 2003, p. 46).

Não se trata, portanto, ao contrário de muitos países, de descentralização administrativa, que deriva do aparelho político-administrativo do Estado, mas política, que transcende a descentralização administrativa, estando ligada à idéia de direito autônomo e "[...] à temática da liberdade, e, portanto, diretamente aos diversos conceitos de democratização e pluralismo." (BOBBIO E PASQUINO, 1999, p. 335). Na descentralização política, informa Montoro (1975), o governo local possui capacidade de criar o direito e agir em sua conformidade, enquanto que, na descentralização administrativa, ele apenas age em conformidade com o direito.

Outra característica do ordenamento jurídico da Federação brasileira é a reprodução vertical da estrutura político-administrativa para os três níveis territoriais que compõem a federação, fenômeno que Castro (2005) denomina isonomia e que Mello (1971) denomina de síndrome da simetria.

Todos os municípios brasileiros, desde a capital de São Paulo, uma das mais importantes cidades do mundo, até a mais pobre comuna do remoto sertão, têm não só a mesma forma de governo como os mesmos poderes, a mesma vasta competência para fazer quase tudo - desde que possam - e a mesma irresponsabilidade para não fazer tudo que não quiserem [...]. Desvirtuada dessa forma, a instituição municipal perde parte de sua flexibilidade e de sua viabilidade, pois se espera de Municípios paupérrimos e prósperos, grandes e pequenos, rurais e metropolitanos, uma atuação da mesma natureza, do mesmo tipo, da mesma amplitude. (MELLO, 1971, p. 45-49).

Mas a existência da simetria não necessariamente determina uma rigidez fática, pois pesquisas como as de Castro demonstram que a criação dos conselhos e as políticas sociais tiveram diferentes resultados segundo a sua aplicação no território brasileiro e, assim, "[...] mesmo com o suporte de uma base legal, o espaço diferencia-se em função das instituições moldadas pela história das sociedades locais." (2003, p. 24). Santos Junior (2001) também argumenta que os municípios são bastante diferenciados, tanto na forma como se estruturam para garantir os direitos sociais, civis e políticos 
quanto no grau de desigualdade econômica, renda, educação e acesso aos equipamentos e serviços urbanos. Segundo Santos e Silveira, essa realidade é explicada porque o Brasil

[...] dispõe de um território fisiograficamente diferenciado, com uma grande variedade de sistemas naturais sobre os quais a história foi se fazendo de um modo também diferenciado. A presença humana e a presença econômica são matizadas segundo os diversos momentos de início da ocupação e conforme as respectivas densidades atuais. É assim que, a partir das heranças, isto é, das solicitações originais próprias a cada momento do passado, e da participação das diversas parcelas do país nas lógicas econômicas, demográficas, políticas contemporâneas, produz-se o verdadeiro mosaico de regiões que hoje constitui a formação socioterritorial brasileira. (2001, p. 249-250).

Dessa forma, a simetria da federação brasileira tem dupla característica. Do ponto de vista vertical, municípios com milhões ou com algumas centenas de habitantes, cujas realidades são completamente distintas, estão sujeitos às mesmas regras de administração e controle. Do ponto de vista horizontal, mesmo localidades com populações semelhantes, pela sua localização espacial, podem ter comportamentos diferenciados, pois estabelecem relações com o meio, advindas das condições históricas, sociais, econômicas e políticas locais, como esclarece Castro "[...] as diferenças vão muito além do problema do tamanho da população ou riqueza, mas encontramse profundamente inscritas nos territórios das sociedades locais." (2005, p.137).

Krell (2003) salienta que houve tentativas constitucionais de buscar formas diferenciadas de administração local. Cita a Constituição de 1967, que estabelecia o preceito de uma organização municipal variável. No entanto, as exigências dessa própria Constituição, sobretudo relacionadas à obrigatoriedade do sistema de divisão de poderes entre os órgãos políticos locais, não permitiram que fossem adotadas outras formas organizativas. Mesmo assim, salienta, "A uniformidade das instituições de governo local no Brasil tem resultado mais da tradição e da imitação do que de imposições legais." (2003, p. 59). Essa tradição se configurou num modelo bastante característico, cujo ordenamento político exige que governo local seja sinônimo de município, não havendo nenhuma outra forma de autonomia local. 
Mas, se na literatura existem críticas a esse sistema simétrico, por outro lado, não existem indicações de que representa o contraponto à lógica simétrica, ou seja, a autonomia municipal, que permite respeitar as características locais do território.

Para a Constituição de 1889, o Brasil era a "[...] união perpétua e indissolúvel das suas antigas Províncias, em Estados Unidos do Brasil”, e os municípios teriam sua autonomia assegurada, no que dizia respeito a seu peculiar interesse, sendo, entretanto subordinados à organização dos Estados. A Constituição de 1934 repetia a Constituição anterior, afirmando que o a nação brasileira era formada "[...] pela união perpétua e indissolúvel dos Estados, do Distrito Federal e dos Territórios em Estados Unidos do Brasil" e determinava que cabia aos estados garantir a autonomia dos municípios. Porém, ao contrário da anterior, enumera algumas das suas atribuições, relacionadas à eletividade de prefeito e vereadores, decretação dos impostos, taxas e organização de serviços locais, sem explicitar quais eram esses serviços. A Constituição de 1937 manteve, em linhas gerais, as mesmas funções em relação aos municípios, extraindo a autonomia.

Para a Constituição de 1946, a União compreendia os Estados, o Distrito Federal e os Territórios, e a autonomia municipal estaria assegurada pela eletividade do prefeito e vereadores e pela administração própria, que dizia respeito à capacidade de arrecadar impostos e tributos, bem como de organizar os serviços locais, embora esses não fossem especificados. Essa constituição criou o que é hoje o Fundo de Participação dos Municípios - FPM , entendendo que a autonomia consistia em letra morta, caso não fossem asseguradas as condições materiais à sua efetivação.

Para as Constituições de 1967 e 1969, o Brasil era “[...] uma República Federativa, constituída sob o regime representativo, pela união indissolúvel dos Estados, do Distrito Federal e dos Territórios". Asseguravam a autonomia municipal através da eleição das autoridades municipais, pela administração própria naquilo que considerava interesses peculiares dos municípios, sobretudo relacionados à arrecadação, aos serviços locais, sem entretanto, nominá-los. 
A Constituição de 1988, entretanto, declarou que a República Federativa do Brasil é "[...] formada pela união indissolúvel dos Estados e Municípios e do Distrito Federal [...]", tornando o governo local autônomo, conforme destacou Camargo:

\begin{abstract}
A contribuição específica da Constituição de 1988 à prática do federalismo foi a de conformar juridicamente, em seu artigo 18, o município como ente federativo, em posição equilavente à dos estados e à do Governo Federal. Esse fato inédito no constitucionalismo e na jurisprudência internacional institucionalizou, em âmbito superior, um pacto federativo tipicamente brasileiro, e que é a velha aspiração coletiva de várias gerações de homens públicos, calcada na velha tradição do municipalismo, datada de mais de 400 anos." (1999, p. 100).
\end{abstract}

Esse retrospecto constitucional serve como referência para mostrar que o município foi assumindo cada vez mais funções e tornou-se instância política fundamental para a vida local, com capacidade de decisão independente dos outros níveis de poder, configurando-se como uma entidade territorial autônoma, com capacidade de governo político próprio. Segundo a Constituição de 1988, aos municípios compete:

- legislar sobre assuntos de interesse local;

- suplementar a legislação federal e a estadual no que couber;

- instituir e arrecadar os tributos de sua competência, bem como aplicar suas rendas, sem prejuízo da obrigatoriedade de prestar contas e publicar balancetes nos prazos fixados em lei;

- criar, organizar e suprimir distritos, observada a legislação estadual;

- organizar e prestar, diretamente ou sob regime de concessão ou permissão, os serviços públicos de interesse local, incluído o de transporte coletivo, que tem caráter essencial;

- manter, com a cooperação técnica e financeira da União e do Estado, programas de educação infantil e de ensino fundamental;

- prestar, com a cooperação técnica e financeira da União e do Estado, serviços de atendimento à saúde da população; 
- promover, no que couber, adequado ordenamento territorial, mediante planejamento e controle do uso, do parcelamento e da ocupação do solo urbano;

- promover a proteção do patrimônio histórico-cultural local, observada a legislação e a ação fiscalizadora federal e estadual.

Como se observa, o espectro de ação dos governos municipais, bem como sua capacidade de decisão, é amplo. Tais competências, segundo Santos Junior, deram condições aos municípios

[...] para elaborar e ser regidos por sua própria lei orgânica, obviamente desde que atendidos os princípios, preceitos e competências estabelecidos pela Constituição Federal e pelas Constituições dos respectivos estados de que fazem parte. Na sua esfera de competências, incluem-se, por exemplo, a autonomia para determinar sua organização administrativa, na forma de secretarias, órgãos de governo e empresas municipais, além da responsabilidade sobre todas as políticas de interesse local, na forma de organizadores e prestadores de serviços públicos e de legisladores de tais políticas." (2001, p. 17).

Essa característica da federação brasileira permite às municipalidades, em certa medida, diversificar as formas de prestação dos serviços locais, respeitando as características de cada lugar, neutralizando, em parte, os efeitos simétricos das imposições verticais. Igualmente, a autonomia oferece a condição da organização das relações internas do município, ao mesmo tempo que, pela integração daquele espaço territorial no sistema político nacional, permite acessar o conjunto de possibilidades oferecidas pelo pacto federativo. Desse modo, seja pela organização das relações locais internas ou externas, a divisão territorial adquire um sentido de oportunidade para as comunidades políticas locais.

\section{CONSIDERAÇÕES FINAIS}

O presente texto mostrou que a reflexão sobre essa trajetória do conceito de território evidencia que as divisões territoriais fazem parte da própria trajetória humana, de modo que o significado da divisão territorial vem passando por contínuas modificações, em função de novos valores e funções 
que emergem da delimitação de áreas. Em consequência, pode-se admitir que a criação de unidades políticas, independentemente da escala de compartimentação, é um fenômeno inerente à história social. As partições são um elemento central do estabelecimento da vida comunitária, que requer a divisão territorial como forma de organização política, pois desse modo é possível estruturar e organizar as relações internas dos grupos, ao mesmo tempo que se permite o reconhecimento, pelo outro, da existência política dessa comunidade. Desse modo, tanto do ponto de vista interno como externo, o território expressa a possibilidade da organização política, o que proporciona certo nível de autonomia do grupo e a inserção no sistema de relações interestatais. Embora cada país tenha uma forma diferente de organizar a sua divisão política, a comparação entre os governos locais mostra que o espaço é dividido porque o reconhecimento de uma comunidade política decorre do reconhecimento da jurisdição sobre uma porção do espaço e, isso estabelece uma identidade política, da comunidade, diante do conjunto.

No Brasil, muitas explicações foram dadas na procura de entender o porquê da divisão do território em municípios. Tais explicações, entretanto, têm caráter conjuntural. Decorre da nossa leitura que a divisão territorial tem origem estrutural, pois a relação entre sociedade e espaço é o mais forte componente da compartimentação. Isso permite entender por que a divisão territorial tem tamanho dinamismo no tempo e no espaço.

\section{REFERENCIAS}

BLASI, P. H. A descentralização como instrumento da justiça social - o município brasileiro: autonomia em crise. Revista Legis, n. 5 - jun./1982, p. 924. Disponível em: <//Platao/www/arquivos/RevistasCCJ>. Acesso em: 31/7/2008.

BRASIL. Constituição brasileira do ano de 1988. Disponível em: <http://www.presidencia.gov.br/legislacao/constituicao/>. Acesso em: julho de 2008.

BRASIL. Constituição brasileira do ano de 1867/69. Disponível em: $<h t t p: / / w w w . p r e s i d e n c i a . g o v . b r / l e g i s l a c a o / c o n s t i t u i c a o />$. Acesso em: julho de 2008.

BRASIL. Constituição brasileira do ano de 1934. Disponível em: <http://www.presidencia.gov.br/legislacao/constituicao/>. Acesso em: julho de 2008.

BRASIL. Constituição brasileira do ano de 1889. Disponível em: <http://www.presidencia.gov.br/legislacao/constituicao/>. Acesso em: julho de 2008. 
BOBBIO, N.; MATTEUCCI, N.; PASQUINO, G. Dicionário de política. Vol. I, 12. ed. Brasília: Editora da UnB, 1999.

CALDAS, E. L. O processo de criação de municípios no Estado de São Paulo entre 1991 e 1996: uma abordagem institucionalista. 2002. Dissertação (Mestrado em Ciência Política). Fundação Getúlio Vargas, São Paulo.

CASTRO, I. E. de. Instituições e território: possibilidades e limites ao exercício da cidadania. Geosul. V.18, n. 36, jul./dez. - Florianópolis: Editora da UFSC, 2003.

CASTRO, I. E. de. Geografia e política: território, escalas de ação e instituições. Rio de Janeiro: Bertrand Brasil, 2005.

CORRALO, G. A autonomia do município na federação brasileira. 2004. (Mestrado). Curso de Mestrado Interinstitucional da Universidade Federal do Paraná e Universidade de Passo Fundo. Curitiba.

CORRALO, G. A autonomia municipal como um direito fundamental na Constituição brasileira. 2006. Tese (doutorado). Programa de Pós-Graduação em Direito, Universidade Federal do Paraná. Curitiba.

COX, K. R. Redefining 'territory'. In: SCOTT, A. J. Metropolis: From the division of labour to urban form. Berkerley and Los Angeles: University of California Press, 1988.

GOTTMANN, J. The significance of territory. The University Press of Virginia, 1973.

HAESBAERT, R. Des-desterritorialização e identidade: a rede "gaúcha" no nordeste. Rio de Janeiro: EDUFF, 1997.

HAESBAERT, R. O mito da desterritorialização. Rio de Janeiro: Bertrand Brasil, 2004.

KATZ, E. Governo local autônomo nos Estados Unidos. U.S Department of State, 2004. Disponível em:

<http://usinfo.state.gov/journals/itdhr/0499/ijdp/katz.htm>. Acesso em: 3/8/2008.

KRELL, A. J. O município no Brasil e na Alemanha. São Paulo: Oficina Municipal, 2003.

LIMA, M. H. P. O processo de emancipação municipal no Estado do Espírito Santo. 2000. Dissertação (Mestrado em Geografia). Instituto de Geociências. Universidade Federal do Rio de Janeiro, Rio de Janeiro.

MONTORO, E. F. O município na Constituição Brasileira. São Paulo: Editora da Universidade Católica, 1975.

MOURA, R.; ULTRAMARI, C. Territorialidades em movimento. Metrópole, grande Curitiba: teoria e prática. Curitiba: IPARDES, 1994.

NORONHA, R. Emancipação municipal: implicações espaciais da divisão político-administrativa do território fluminense. 1997. Dissertação (Mestrado em Geografia). Instituto de Geociências, Universidade Federal do Rio de Janeiro. Rio de Janeiro. 
OLOWU, D. Governo local na Nigéria e no Brasil: um estudo comparativo. In: Revista de Administração Municipal - ano XXIX, número 165, Rio de Janeiro: IBAM, 1982.

RAFFESTIN, C. Por uma geografia do poder. São Paulo: Ática, 1993.

RECH, A. U. O poder local: formação e papel dos municípios no Estado brasileiro. 2000. (Dissertação) - Mestrado em Direito do Estado, Universidade Federal do Paraná/Universidade Federal de Caxias do Sul, Caxias do Sul.

RODRIGUES, P. H. O sistema de governo local do Estado de Nova lorque. In: Revista de Administração Municipal, v. 42, n. 215, abr./jun. 1995. Rio de Janeiro, 1995.

SANTOS, M. O País distorcido. São Paulo: Publifolha, 2002.

SILVEIRA, M. L. Brasil: território e sociedade no início do século XXI. Rio de Janeiro: Record, 2001.

Por uma outra globalização: do discurso único à consciência universal. São Paulo: Record, 2000.

.BECKER, B. K. (et al.). Território, territórios: ensaios sobre 0 ordenamento territorial. 2. ed. Rio de Janeiro: DP\&A, 2006.

.O retorno do território In: SANTOS, M. et al. (Orgs.). Território: globalização e fragmentação. São Paulo: HUCITEC/ANPUR, 1996.

MELLO, D. L. de. O município na organização nacional: bases para uma reforma no regime municipal brasileiro. Rio de Janeiro: IBAM, 1971.

SANTOS JUNIOR, O. A. dos. Democracia e governo local: dilemas da reforma municipal no Brasil. Rio de Janeiro: Revan - FASE, 2001.

SAQUET, M. A. Abordagens e concepções de território. São Paulo: Expressão Popular, 2007.

SOUZA, M. J. L. de. O território: sobre espaço e poder, autonomia e desenvolvimento. In: CASTRO, I. E. de; COSTA, P. C.; CORRÊA, R. L. (Orgs.). Geografia: conceitos e temas. 5. ed. Rio de Janeiro: Bertrand Brasil, 2003.

TOMIO, R. de L. C. Instituições, processo decisório e relações ExecutivoLegislativo nos Estados: estudo comparativo sobre o processo de criação de municípios após a Constituição de 1988. 2002. Tese (Doutorado em Ciências Sociais). Departamento de Ciência Política. Instituto de Filosofia e Ciências Humanas. Universidade Estadual de Campinas. São Paulo. 